\title{
Detecting sand-dust storms using a wind-profiling radar
}

\author{
WANG Minzhong $^{1 *},{\text { MING } \mathrm{Hu}^{2}, \text { HUO Wen }}^{1}, \mathrm{XU}$ Hongxiong $^{3}$, LI Jiangang ${ }^{1}$, LI Xingcai ${ }^{4}$ \\ ${ }^{1}$ Institute of Desert Meteorology, China Meteorological Administration, Urumqi 830002, China; \\ ${ }^{2}$ Northwest Air Traffic Management Bureau, Civil Aviation Administration of China, Xi'an 710082, China; \\ ${ }^{3}$ State Key Laboratory of Severe Weather, Chinese Academy of Meteorological Science, Beijing 100081, China; \\ ${ }^{4}$ School of Physics \& Electrical Information Engineering, Ningxia Key Laboratory of Intelligent Sensing for the Desert \\ Information, Ningxia University, Yinchuan 750021, China
}

\begin{abstract}
Sand-dust storm is a type of disastrous weather, typically occurring in arid and semi-arid climates. This study selected a region in the hinterlands of the Taklimakan Desert, called the Tazhong region, as the experimental area to quantitatively estimate the particle concentrations of sand-dust storms using the boundary layer wind-profiling radar. We thoroughly studied the radar echo signals and reflectivity factor features during the sand-dust storms. The results indicate that (1) under sand-dust storm conditions, boundary layer wind-profiling radar cannot capture the complete information regarding horizontal wind velocity and direction, but it can obtain the backscattering intensity of sand-dust storms; and (2) during sand-dust storms particle size distributions in the surface layer closely resemble log-normal distributions, with sand-dust particles sizes of 90-100 $\mu \mathrm{m}$ accounting for the maximum particle probability. Retrieved particle size distributions at heights of 600, 800, and $1000 \mathrm{~m}$ follow log-normal distributions, and the expected value of particle diameter decreases gradually with increasing height. From the perspective of orders of magnitude, the retrieved results for particle number concentrations and mass concentrations are consistent with previous aircraft-detected results, indicating that it is basically feasible to use boundary layer wind-profiling radar to quantitatively detect the particle concentrations of dust storms.
\end{abstract}

Keywords: echo signal; mass concentration; retrieval method; sand-dust storm; wind-profiling radar; Taklimakan Desert

Citation: WANG Minzhong, MING Hu, HUO Wen, XU Hongxiong, LI Jiangang, LI Xingcai. 2017. Detecting sand-dust storms using a wind-profiling radar. Journal of Arid Land, 9(5): 753-762. doi: 10.1007/s40333-017-0031-5

\section{Introduction}

The Taklimakan Desert, the world's second largest moving sand-dune desert, is in the central part of mid-latitude Eurasia in the Northern Hemisphere and covers approximately $337.6 \times 10^{3} \mathrm{~km}^{2}$. The region is characterized by little precipitation, sparse vegetation, and frequent sand-dust storms (Wang et al., 2016). A sand-dust storm is a type of disastrous weather and is typically occurring in arid and semi-arid climates (Wang et al., 2013). The Taklimakan Desert is definitely one of world's centres of sand-dust storms. Generally speaking, sand-dust storms not only cause massive direct and indirect losses in agriculture and industrial production, but also have an adverse effect on human health and even ecological environments. Additionally, the recurring sand-dust storms could have a long-term influence on climate. Therefore, the quantitative

*Corresponding author: WANG Minzhong (E-mail: yurenkeji@sina.com)

Received 2016-10-20; revised 2017-07-10; accepted 2017-08-11

(C) Xinjiang Institute of Ecology and Geography, Chinese Academy of Sciences, Science Press and Springer-Verlag GmbH Germany 2017 
monitoring of sand-dust storms is of great significance from the perspectives of disaster prevention and mitigation, ecological and environmental protection, and sustainable development. Yet, high-resolution monitoring data for sand-dust storms in the Taklimakan Desert are scarce.

Satellite remote sensing technology and Micro Pulse Lidar (MPL) technology are commonly used for monitoring sand-dust storms. Satellite remote sensing technology can monitor the coverage and transport routes of sand-dust storms using infrared bands, but it is not able to extract such dada as the specific vertical structure of sand-dust storms, sand content in the air, sand-dust particle concentrations. MPL technology can observe the vertical structure, composition, and optical properties of sand-dust aerosols in real time. However, owing to short wavelength and low transmitted power, MPL cannot penetrate the entire profile of strong sand-dust storms.

In recent years, wind-profiling radar has emerged as a popular atmospheric remote sensing technology. Over the past several decades, with the help of wind-profiling radar, researchers have conducted many studies focussing on atmospheric wind field observations (Angevine, 1997; Lothon et al., 2002), numerical weather forecasting (Kuo et al., 1987), precipitation processes (Fukao et al., 1985; Ralph, 1995; Gage et al., 1996; Rao et al., 1999; Deshpande and Raj, 2009), atmospheric turbulence and boundary layer thickness measurement (Hocking, 1983, 1985; Angevine et al., 1994; Hashiguchi et al., 1996; Gossard et al., 1998; Hermawan and Tsuda, 1999), inversion of raindrop size distributions (Currier et al., 1992). However, the quantitative monitoring of sand-dust storms via wind-profiling radar is a topic that has only been touched on lightly.

With regard to monitoring altitude, wind-profiling radar is categorized into boundary layer wind-profiling radar, troposphere wind-profiling radar, and stratosphere wind-profiling radar (He, 2006). The electromagnetic wavelength of boundary layer wind-profiling radar is dozens of centimetres. When boundary layer wind-profiling radar is used under the sand-dust storm conditions, more transmitted energy is scattered back by upper-air sand-dust particle. Additionally, owing to the narrow pulse beam width, more detailed vertical profiles of sand-dust storms can be obtained. In this study, we utilized the CFL-03 boundary layer wind-profiling radar system to detect sand-dust storm processes. We analysed the echo signal features of sand-dust storms, calculated the radar reflectivity factor of sand-dust storms, and retrieved sand-dust mass concentrations by using radar reflectivity factor data.

\section{Materials and methods}

\subsection{Study area and data collection}

The study area, called the Tazhong region, is in the hinterlands of the Taklimakan Desert within the mid-latitude of the Eurasian Continent $\left(39^{\circ} 00^{\prime} \mathrm{N}, 83^{\circ} 40^{\prime} \mathrm{E}\right.$; Fig. 1a). The average annual precipitation is less than $35 \mathrm{~mm}$. The Urumqi Institute of Desert Meteorology of the China Meteorological Administration set up the Taklimakan Experimental Station for Atmospheric Environment Observation and the station is equipped with an $80-\mathrm{m}$ high meteorological observation tower (Fig. 1b). From March to May 2014, we deployed a CFL-03 mobile boundary layer wind-profiling radar system to detect sand-dust storms. Prior to experimentation, the technical parameters of the wind-profiling radar were measured and repeatedly calibrated (Wang et al., 2013). Additionally, sand traps were installed at heights of 47,63, and $80 \mathrm{~m}$ on the meteorological observation tower to collect sand samples during the sand-dust storms.

The data used in this paper were mainly collected by the wind-profiling radar, including original power spectrums, signal-to-noise ratios, horizontal wind velocities, and wind directions. The sand-dust particle size distribution data collected from the meteorological observation tower were also used.

\subsection{Retrieval method for mass concentrations of the sand-dust storms}

The specific methods and procedures for mass concentration retrieval are as follows: (1) using the wind-profiling radar to continuously detect sand-dust storms for obtaining the echo power spectrum of the storms; (2) using the radar meteorology equation to calculate the reflectivity 
factor of the sand-dust storms; (3) calculating the granularity probabilities from upper-air sand-dust at various heights based on the data from the meteorological observation tower; (4) using the radar reflectivity factor and granularity probabilities to calculate number concentrations and particle size distributions; and (5) calculating the particle mass concentrations based on the obtained particle size distributions.
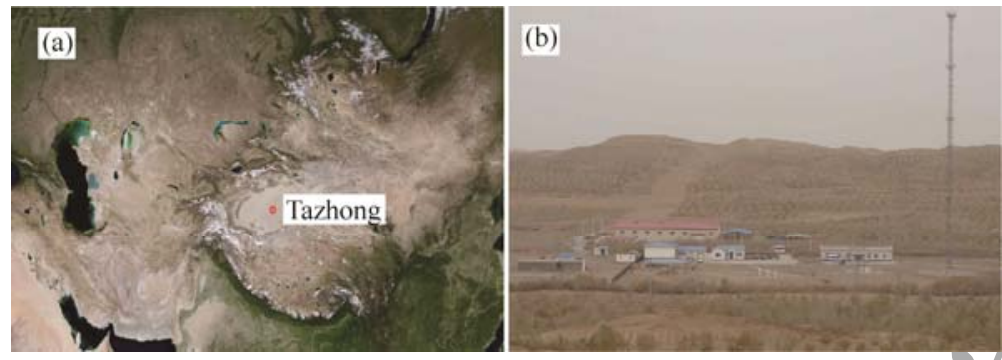

Fig. 1 Schematic map of the study area

\subsection{Description of the sand-dust storm processes}

Two sand-dust storms occurred in the hinterlands of the Taklimakan Desert on 23 April and 17 May, 2014 (Table 1). On 23 April, 2014, observed were floating dust from 08:00 to 09:35 (Beijing time), blowing sand from 09:35 to 14:41, and a sand-dust storm from 14:41 to 24:00. On 17 May, 2014, observed were sand-dust storms from 08:00 to 09:39 and 10:46 to 12:51, blowing sand from $09: 39$ to $10: 46$ and from 12:51 to $14: 10$, floating dust in the rest of time. It should be noted that night-time (00:00-08:00) sand-dust storm weather and category were also observed. But, the start and end times were not recorded.

Table 1 Start and end times of sand-dust weather phenomena

\begin{tabular}{|c|c|c|}
\hline Date & Time & Weather phenomenon \\
\hline \multirow{4}{*}{23 April, 2014} & $: 00-08: 0$ & Floating dust, blowing sand \\
\hline & & Floating dust \\
\hline & $: 35-14: 4$ & Blowing sand \\
\hline & $: 41-24: 0$ & Sand-dust storm \\
\hline \multirow{3}{*}{17 May, 2014} & $: 00-08: 0$ & $\begin{array}{l}\text { Floating dust, blowing sand, sand-dust } \\
\text { storm }\end{array}$ \\
\hline & $: 39,10: 4$ & Sand-dust storm \\
\hline & $: 46,12: 5$ & Blowing sand \\
\hline
\end{tabular}

\section{Results and discussion}

\subsection{Echo signals received by wind-profiling radar during the sand-dust storms}

Turbulent scattering is the basic mechanism of the echo signals received by wind-profiling radar (He, 2006). When a sand-dust storm begins, the air containing sand and dust particles complicates the scattering process. Figure 2 presents the velocity power spectrums detected using the low-mode vertical beam, eastern beam, and northern beam of the wind-profiling radar at 21:33 (Beijing time), 23 April, 2014, and the velocity power spectrum detected using the high-mode vertical beam at 21:35 on the same day. In Figures $2 \mathrm{a}-\mathrm{c}$, only one echo peak is present in each range bin for the low-mode vertical beam, eastern beam, and northern beam power spectrums. The signal is rather distinctive with a definite echo power and a relatively small radial velocity. Figure $2 \mathrm{~d}$ (high-mode velocity power spectrum) implies that an obvious echo peak is present near zero frequency in every range bin below $1500 \mathrm{~m}$, while no clear echo peak appears due to increased interference above $1500 \mathrm{~m}$. This indicates that the echo signals received and detected by the wind-profiling radar during the sand-dust storms are mainly from the heights of $1500 \mathrm{~m}$ and below. The dry air during the sand-dust storm under small turbulent fluctuations results in a very 
weak echo signal from turbulent scattering. When electromagnetic waves from the wind-profiling radar encounter sand-dust particle swarms, the waves are greatly scattered and the energy scattered back by the particle swarms are received by the wind-profiling radar. The scatted energy is reflected on the velocity power spectrum as an apparent echo peak. The signal-producing processing in the wind-profiling radar is mainly associated with sand-dust particles.

(a)

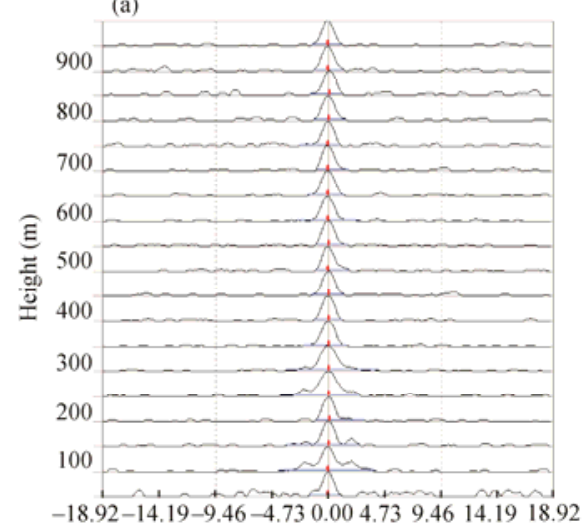

(c)

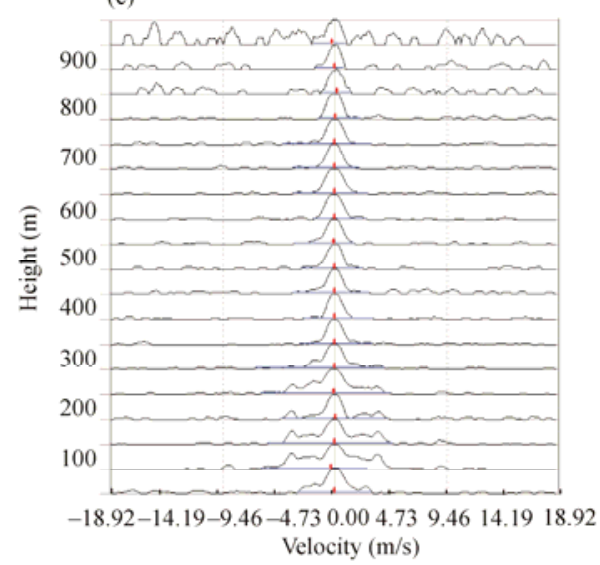

(b)

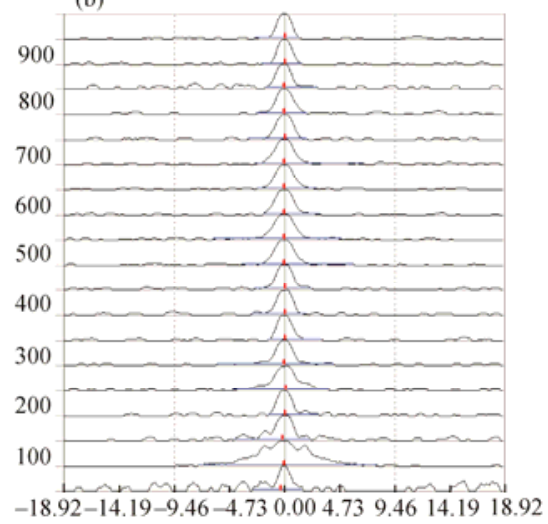

(d)

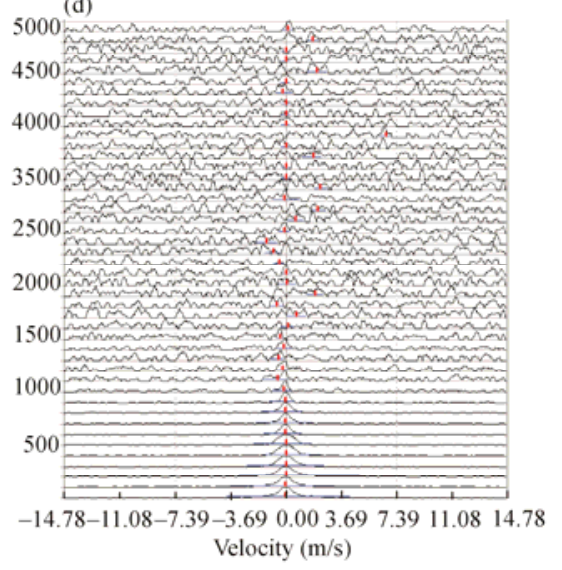

Fig. 2 Velocity power spectrum distributions for the sand-dust storm on 23 April, 2014. (a) Low-mode vertical beam power spectrum at 21:33 (Beijing time); (b) Low-mode eastern beam power spectrum at 21:33; (c) Low-mode northern beam power spectrum at 21:33; (d) High-mode vertical beam power spectrum at 21:35.

Figure 3 presents the observed horizontal wind speed and direction during the sand-dust storm on 23 April, 2014. It should be noted that some observation data for horizontal wind are missing and that there are apparent deviations in the observed data of wind speed and direction. In the velocity power spectrums in Figure 2, the presence of all echo peaks near zero frequency indicates that effective Doppler velocity data could not be obtained by wind-profiling radar. This is likely caused by two factors. First, the echo signals of sand-dust particles are strong, but have poor coherence. It means that the coherence times of the sand-dust signals are not compatible with the coherence accumulation time of the wind-profiling radar, making signals from different frequencies and phases cancel out with each other. Second, the electromagnetic wavelength emitted from the wind-profiling radar is too long to detect the Doppler velocity of individual sand-dust particles. The upper-air sand-dust particles during the sand-dust storms are very dense and distribution of the sand-dust particles is uniform both inside and outside the radar beam, meaning the radar cannot see the differences between sand-dust particle swarms inside and outside the radar beam. The above analysis indicates that when boundary layer wind-profiling radar is used to detect sand-dust storms, the echo signals scattered back by sand-dust particle swarms are relatively strong, while the echo signals from atmospheric turbulence are very weak. Thus, the echo signals from turbulence are typically overwhelmed by those from sand-dust 
particles. Although boundary layer wind-profiling radar cannot detect and obtain horizontal wind velocity and direction accurately, it can capture the backscattering intensity data of sand-dust storms.

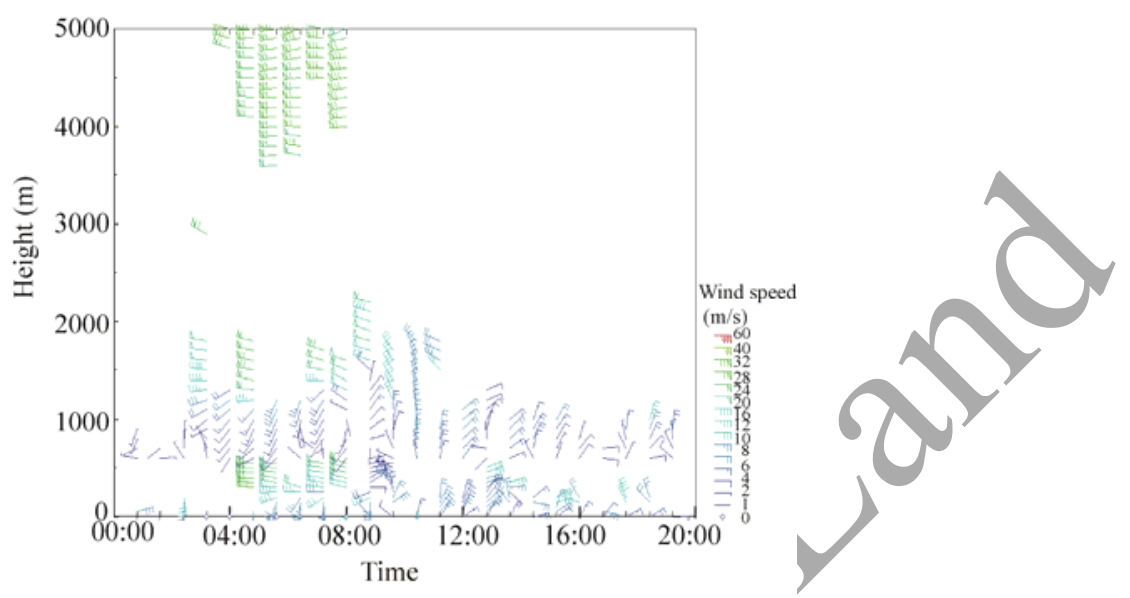

Fig. 3 Horizontal wind speed and direction during the sand-dust storm on 23 April, 2014

\subsection{Reflectivity factor via wind-profiling radar during the sand-dust storms}

Using the radar meteorology equation (Wang et al., 2013), we calculated the radar reflectivity factors $(Z)$ of the sand-dust storms on 23 April and 17 May, 2014. From the radar reflectivity factor profile on 23 April (Fig. 4a), it can be seen that the strong reflectivity factor zone corresponds to the sand-dust storm weather conditions. The radar reflectivity factor during the blowing sand and sand-dust storm varies within a range of $0-15 \mathrm{dBz}$. From the radar reflectivity factor profile on 17 May (Fig. 4b), the processes of floating dust, blowing sand and sand-dust storm can also be clearly observed. A sustained strong reflectivity factor zone emerges at a level below $1000 \mathrm{~m}$, which is highlighted in red and yellow. The reflectivity factor ranges from 0 to 15 $\mathrm{dBz}$, and the sand-dust particles in the sand-dust storm are transported up to a height of no more than $1500 \mathrm{~m}$. The above analysis implies that the reflectivity factor profile from wind-profiling radar can be used to determine the transport height and vertical intensity of sand-dust particles.
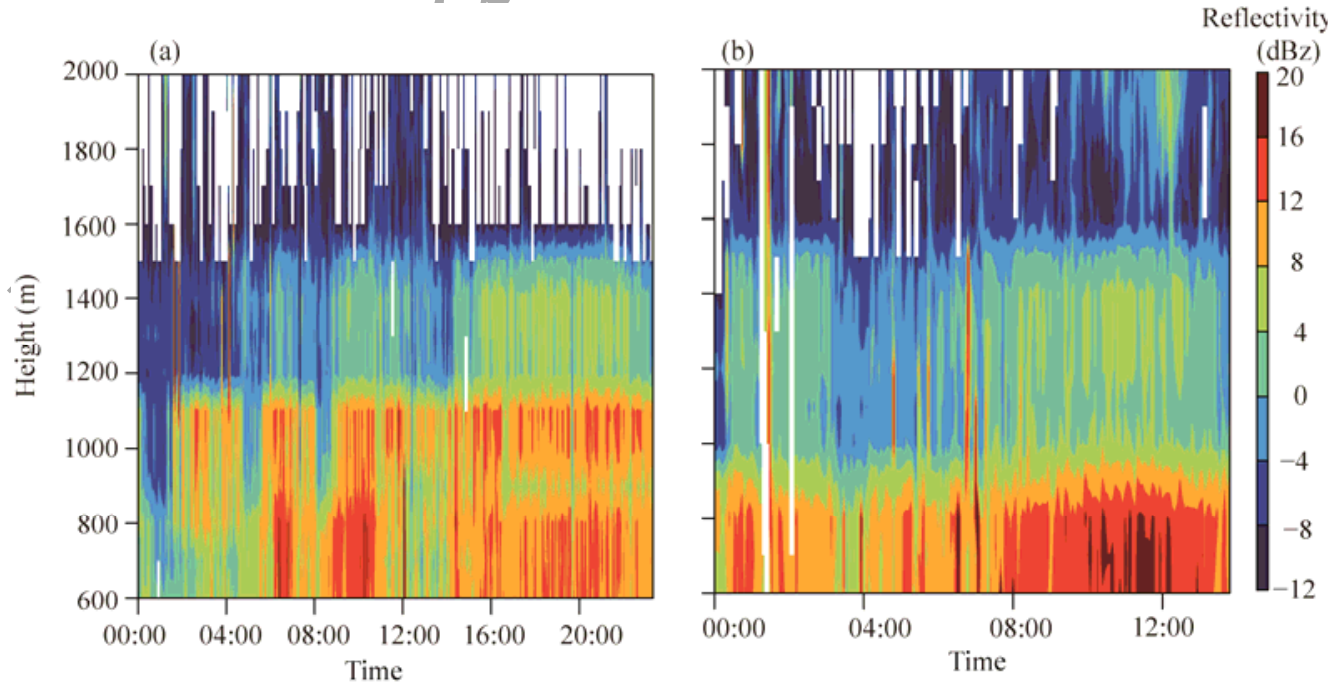

Fig. 4 Radar reflectivity factors of the sand-dust storms on 23 April (a) and 17 May (b), 2014

In order to validate the accuracy of wind-profiling radar for sand-dust storm reflectivity factor detection, we randomly selected a clear day to calculate corresponding equivalent reflectivity 
factors $\left(Z_{e}\right)$. The equation used is presented below (Ruan et al., 2008):

$$
Z_{e}=\frac{\eta \times \lambda^{4}}{\pi^{5}|K|^{2}}=\frac{0.38 \times C_{n}^{2} \times \lambda^{11 / 3}}{\pi^{5}|K|^{2}},
$$

where $\lambda$ is the electromagnetic wavelength $(\mathrm{m}) ; C_{n}^{2}$ is the turbulence refractive index structure constant $\left(\mathrm{m}^{-2 / 3}\right) ; \eta$ is the radar reflectivity $\left(\mathrm{m}^{-1}\right) ; \pi$ is the constant; and $|K|^{2}$ is the square of plural module and the value is 0.3 .

From the radar equivalent reflectivity factors under clear weather conditions in the desert (Fig. 5), we can see that the reflectivity factor is weak during night and increases gradually after sunrise in the morning. This is shown by the rising portion of the parabolic curve in red and yellow in Figure 5. During the period from 17:00 to 19:00, the equivalent reflectivity factor reaches a summit between -7 and $-3 \mathrm{dBz}_{\mathrm{e}}$ with a transport height up to approximately $3500 \mathrm{~m}$. However, after 20:00, the reflectivity factor weakens. The profile reveals the evolution characteristics of the turbulence boundary layer with clear air. Compared to the sand-dust storm weather reflectivity factor profile (Fig. 4), it is clear that the reflectivity factor under clear weather conditions is much weaker. In other words, the backscattering of electromagnetic waves by the turbulence of clear weather is much weaker than that by the sand-dust storms, further illustrating that the accuracy of wind-profiling radar as a detection method for sand-dust reflectivity factors is acceptable.

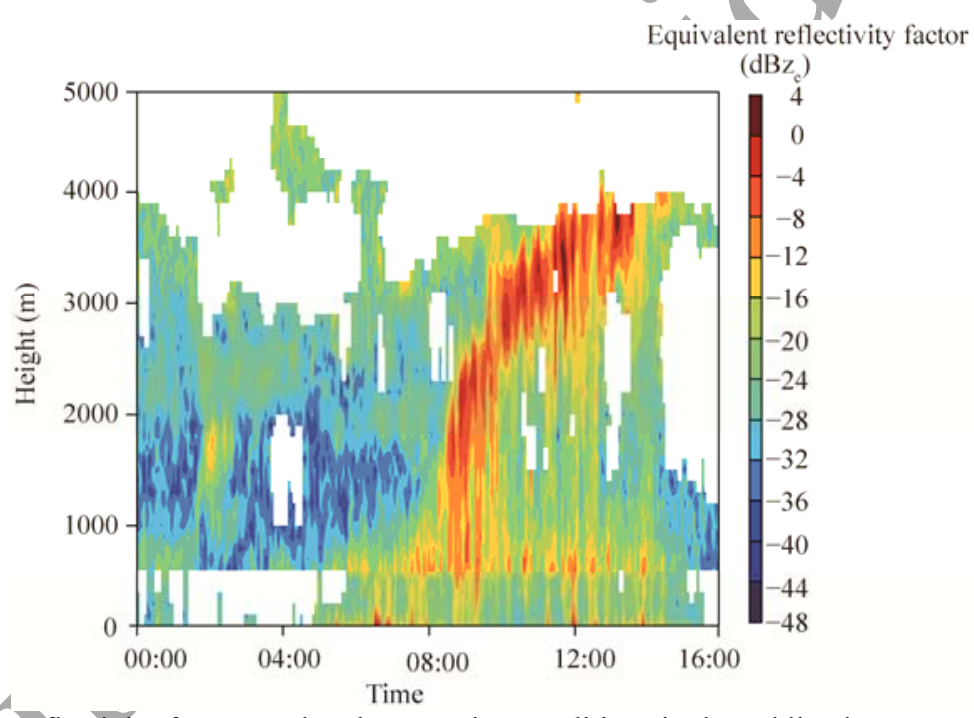

Fig. 5 Equivalent reflectivity factors under clear weather conditions in the Taklimakan Desert on 3 August, 2010

\subsection{Quantitative inversion of the sand-dust concentrations based on wind-profiling radar}

Many studies have proven that the method to detect precipitation processes with ground-based Doppler weather radar can be used to quantitatively retrieve the water content in clouds (Zhang and Wang, 1995; Zhang et al., 2001). The same principle is introduced to retrieve the number concentrations and mass concentrations of upper-air sand-dust particles during the sand-dust storm processes. The quantitative inversion method is described below.

First, sand traps were installed at heights of 47,63 , and $80 \mathrm{~m}$ on the meteorological observation tower. Second, sand-dust samples at the three heights under sand-dust storm weather conditions were collected on 23 April, 2014. Third, using a Malvern laser granularity analyser, the particle size distributions of the sand-dust samples were analysed. Figure 6 indicates that particle size distributions generally follow a log-normal distribution with sand-dust particles sizes $90-100 \mu \mathrm{m}$ accounting for the maximum particle probability. Based on the log-normal distribution of the granularity (Dong, 1997), the probability function for a log-normal distribution (Equation 2) is applied to the fittings of the sand-dust samples collected at heights of 47,63 , and $80 \mathrm{~m}$, respectively (Fig. 6). 


$$
p(D)=\frac{a}{\sqrt{2 \pi} \sigma D} \exp \left(-\frac{(\ln D-m)^{2}}{2 \sigma^{2}}\right),
$$

where $p(D)$ is the particle probability $(\%) ; D$ is the sand-dust particle diameter $(\mu \mathrm{m}) ; m$ is the average value of $\ln D ; \sigma$ is the standard deviation of $\ln D$; and $a$ is an adjustment constant used to bring the fitting trend even closer to the actual value. The fitting results are listed in Table 2.

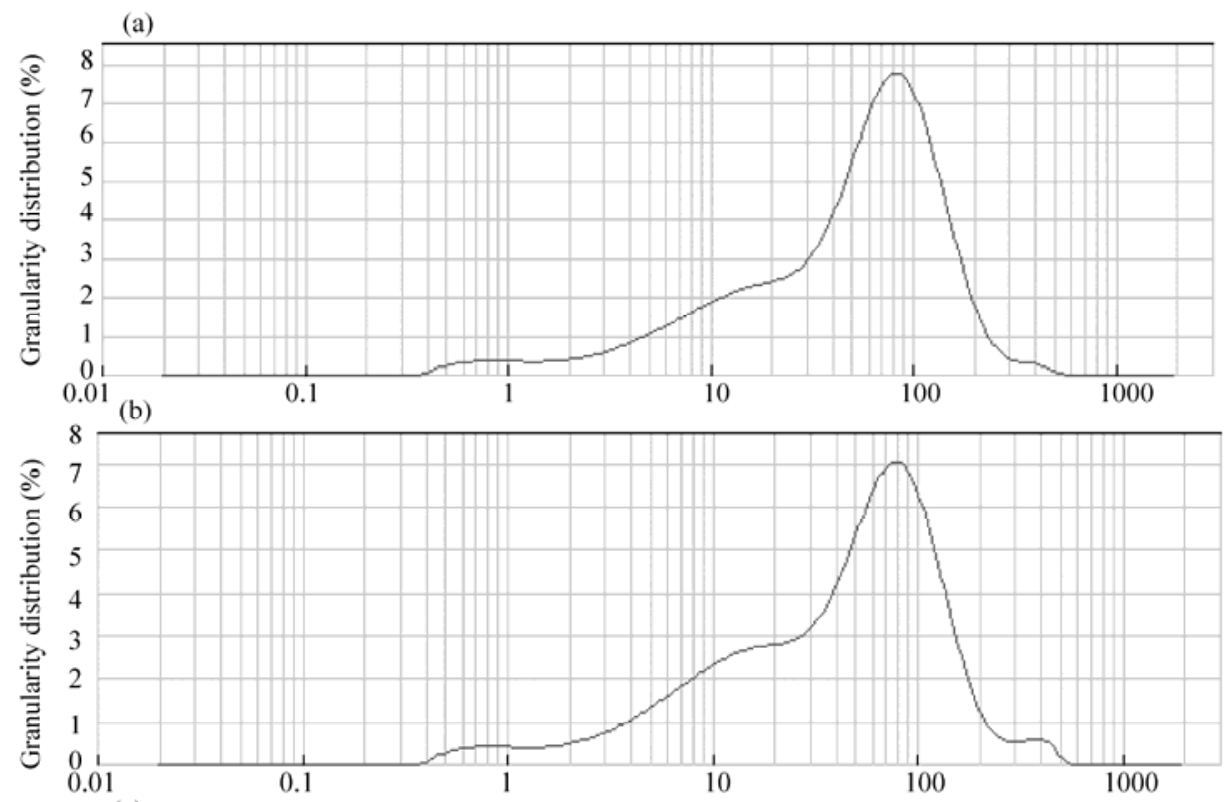

(c)

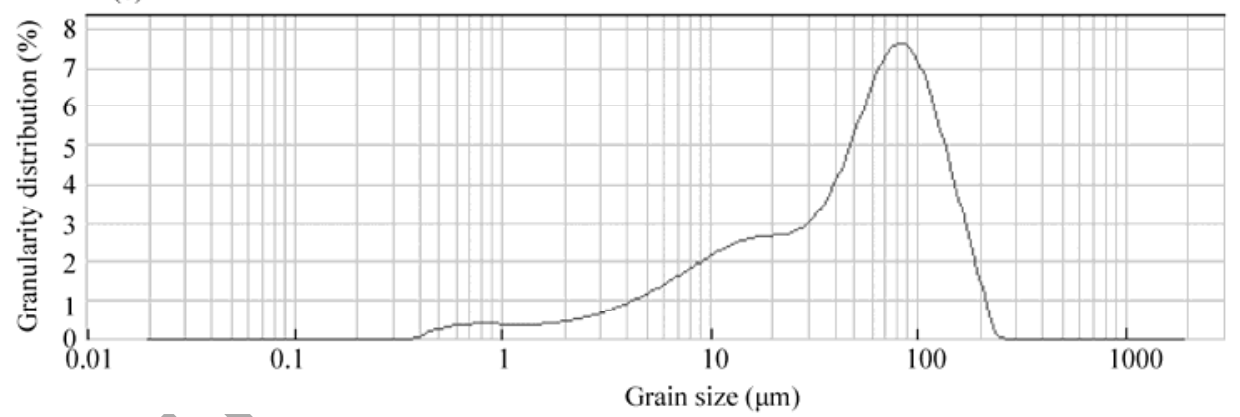

Fig. 6 Granularity distributions at heights of 47 (a), 63 (b), and 80 (c) m during the sand-dust storm on 23 April, 2014

Table 2 Gaussian fitting parameters and correlation coefficients at different sampling heights

\begin{tabular}{ccccc}
\hline Height $(\mathrm{m})$ & $a$ & $m$ & $\sigma$ & \multicolumn{2}{c}{0.925} \\
\hline 47 & 0.225 & -2.579 & 0.748 & 0.918 \\
63 & 0.225 & -2.701 & 0.791 & 0.928 \\
80 & 0.225 & -2.910 & 0.821 & 0.928 \\
\hline
\end{tabular}

Note: $a$, adjustment constant; $m$, average value of $\ln D ; \sigma$, standard deviation of $\ln D ; r$, correlation coefficient.

From Table 2, adjustment constant $a$ was 0.225 during the sand-dust storm on 23 April. The standard deviation $\sigma$ and average value $m$ vary with different heights, and their variations comply with logarithmic distributions (Dong, 1997). Using the average values $m$ and standard deviations $\sigma$ at heights of 47,63 , and $80 \mathrm{~m}$, we derived the following equations expressing both standard deviation and average value variations in terms of heights.

$$
\begin{aligned}
& m=0.434 \mathrm{e}^{(-1.827 h),} \\
& \sigma=0.081 \mathrm{e}^{(0.847 h)} .
\end{aligned}
$$


The standard deviation and mean values at different heights can be obtained using Equations 3 and 4 . The sand-dust particle probability distribution functions at various heights can be derived from Equation 2.

The relationship between the reflectivity factor $Z$ and the particle size distribution $N\left(D_{j}\right)$ can be written as follows (Zhang and Wang, 1995; Zhang et al., 2001):

$$
Z=\sum D_{j}^{6}=\sum_{D_{j}=0}^{D_{\max }} N\left(D_{j}\right) D_{j}^{6} \Delta D=\sum_{D_{j}=0}^{D_{\max }} N_{0} p\left(D_{j}\right) D_{j}^{6} \Delta D,
$$

where $N_{0}$ is the total number of particles (number concentration of particles); $p\left(D_{j}\right)$ is the probability for a particle diameter of $D_{j}(\%)$; and $\Delta D$ is the particle spacing. The total number of sand-dust particles (Fig. 7) and the particle size distribution (Fig. 8) can be derived from Equation 5. Figure 7 implies that the maximum particle number concentration reaches $110 \times 10^{3}$ particles $/ \mathrm{m}^{3}$ during the sand-dust storm processes. Figure 8 indicates that the values of $N\left(D_{j}\right)$ at heights of 600 , 800 , and $1000 \mathrm{~m}$ generally follow log-normal distributions. The expected values for particle number concentration and particle diameter decrease gradually as height increases.

Mass concentration refers to the sand-dust mass per unit volume of air. The mass concentration equation is as follows:

$$
M=\frac{1}{6} \pi \rho \sum_{j=1}^{N} N\left(D_{j}\right) D_{j}^{3} \Delta D,
$$

where $M$ is the mass concentration $\left(\mu \mathrm{g} / \mathrm{m}^{3}\right) ; \pi$ is the constant; and $\rho$ is the density of the sand-dust, which has a value of $2.65 \times 10^{6} \mathrm{~g} / \mathrm{m}^{3}$.

Using Equation 6, the retrieved $N\left(D_{j}\right)$ can be used to calculate mass concentrations at various heights during the sand-dust storms. Figure 9 indicates that sand-dust mass concentration is relatively high, falling in a range of $200-800 \mu \mathrm{g} / \mathrm{m}^{3}$ at a height of $600 \mathrm{~m}$. As the heights increases, the mass concentration gradually decreases. At a height of $1400 \mathrm{~m}$, mass concentration drops to the range of $50-200 \mu \mathrm{g} / \mathrm{m}^{3}$.

You et al. (1991) installed a particle measuring system on an aircraft to monitor sand-dust particle number concentrations and mass concentrations during the sand-dust storms in the Alxa Desert, Inner Mongolia, China. The monitoring results showed that sand-dust particle number concentration is at most $150 \times 10^{3}$ particles $/ \mathrm{m}^{3}$ at the heights of $2000-3300 \mathrm{~m}$, with a mass concentration between 24 and $340 \mu \mathrm{g} / \mathrm{m}^{3}$. In terms of orders of magnitude, the retrieval results in this paper are in agreement with these aircraft-detected results. This agreement indicates that boundary layer wind-profiling radar is an acceptable method to quantitatively detect sand-dust concentrations.

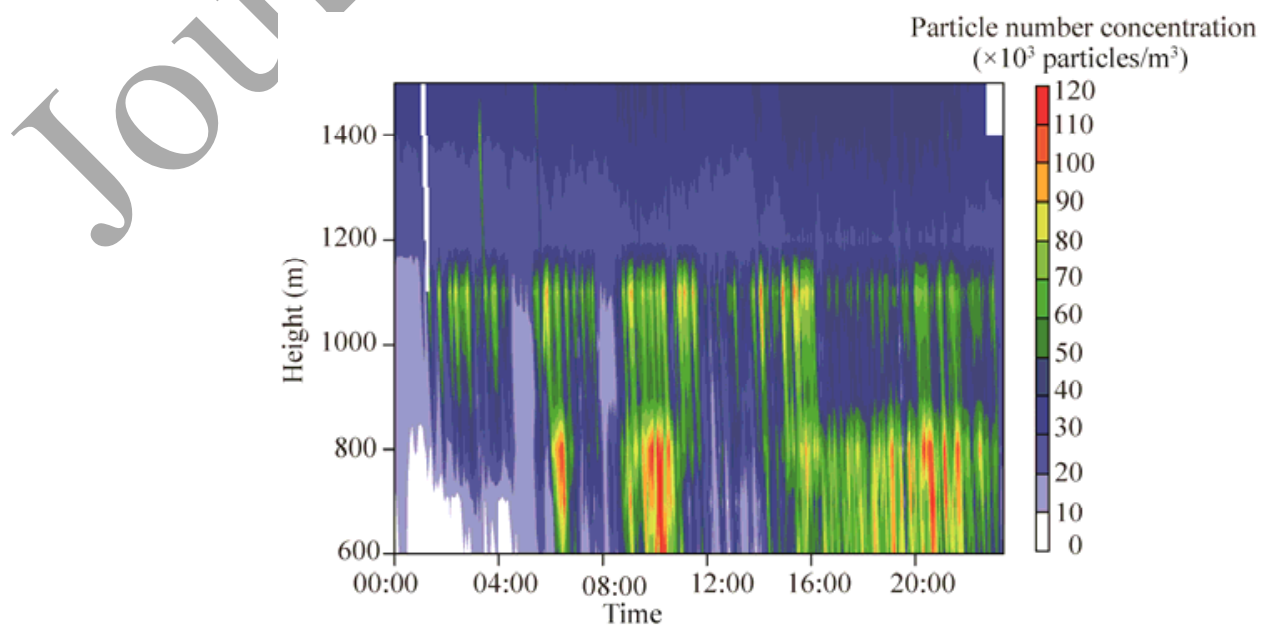

Fig. 7 Sand-dust particle number concentrations during the sand-dust storm on 23 April, 2014 

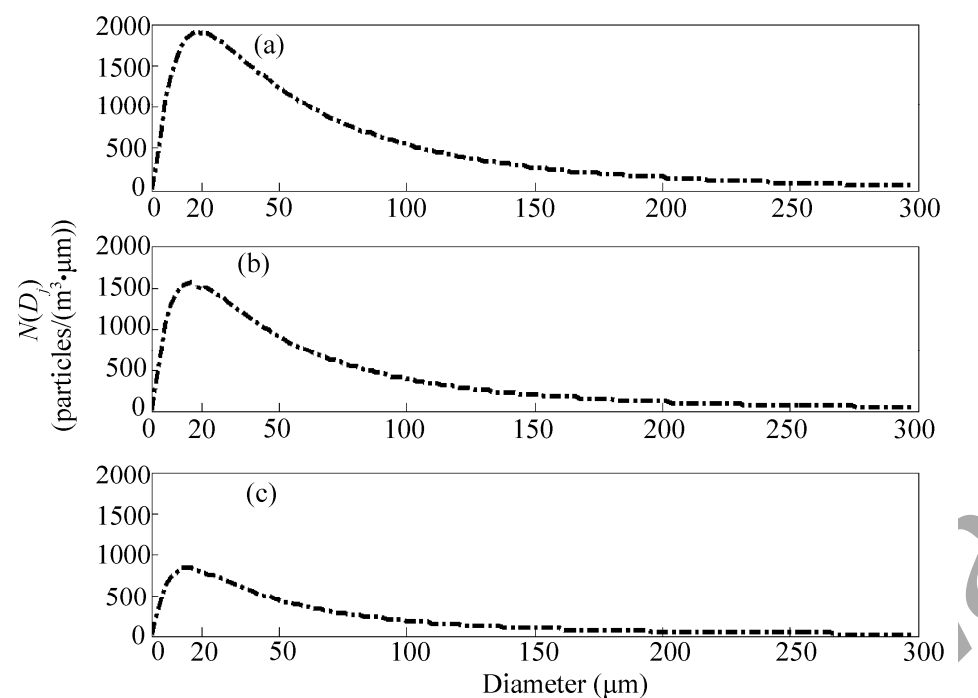

Fig. 8 Particle size distributions $\left(N\left(D_{j}\right)\right)$ at heights of $600(\mathrm{a}), 800$ (b), and $1000 \mathrm{~m}$ (c) at 21:35 on 23 April, 2014

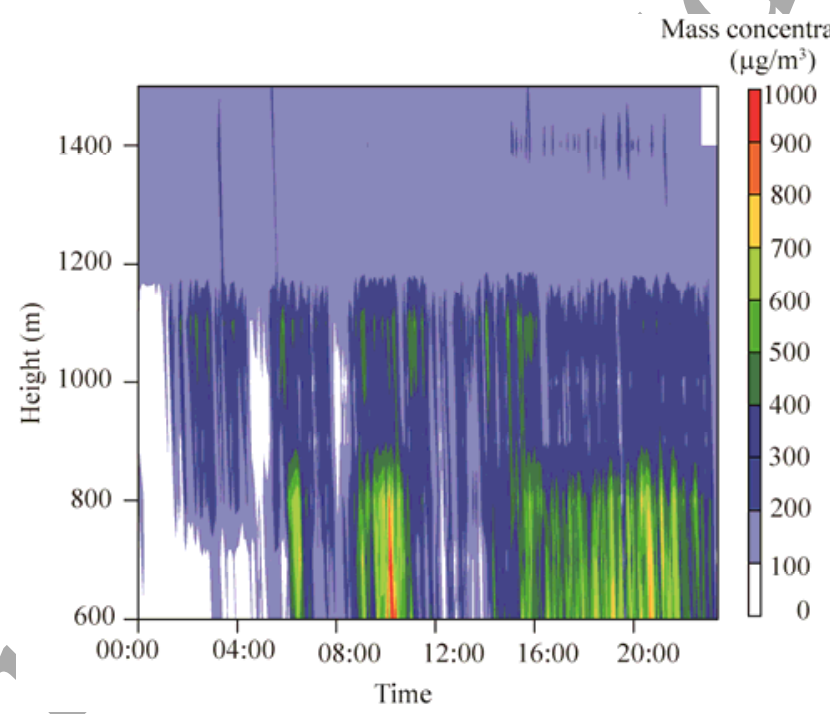

Fig. 9 Mass concentrations of sand-dust particles during the sand-dust storm on 23 April, 2014

\section{Conclusions}

We used a CFL-03 wind-profiling radar system to quantitatively monitor sand-dust storms. Under sand-dust storm weather conditions, the echo signals from turbulence are very weak, meaning that the wind-profiling radar cannot capture complete data of horizontal wind velocity and direction. However, it can obtain the information of the backscattering intensity of sand-dust storms. From the perspective of orders of magnitude, the retrieved results for particle number concentrations and mass concentrations of sand-dust storms in the present study are consistent with previous aircraft detection results. This consistency indicates that it is basically feasible to use wind-profiling radar to quantitatively detect sand-dust particle concentrations. Owing to a lack of upper-air particle size distribution data for sand-dust storms, the accuracy for the retrieved mass concentrations cannot be assured here yet. But, this could be improved through further vertical observation experiments on sand-dust storms. Furthermore, the results reported in this paper should be compared in future with experimental data from other wind-profiling radar systems manufactured by different vendors. 


\section{Acknowledgements}

This work was supported by the National Natural Science Foundation of China $(41775030,41575008,11302111$, 11562017), the China Research Foundation for Desert Meteorology (SQJ2014003) and the China Postdoctoral Science Foundation. The authors would like to thank anonymous reviewers and the editors for their helpful suggestions.

\section{References}

Angevine W M, White A B, Avery S K. 1994. Boundary-layer depth and entrainment zone characterization with a boundary-layer profiler. Boundary-layer Meteorology, 68(4): 375-385.

Angevine W M. 1997. Errors in mean vertical velocities measured by boundary layer wind profilers. Journal of Atmospheric and Oceanic Technology, 14(3): 565-569.

Currier P E, Avery S K, Balsley B B, et al. 1992. Combined use of $50 \mathrm{MHz}$ and $915 \mathrm{MHz}$ wind profilers in the estimation of raindrop size distributions. Geophysical Research Letters, 19(10): 1017-1020.

Deshpande S M, Raj P E. 2009. UHF wind profiler observations during a tropical pre-monsoon thunderstorm-A case study. Atmospheric Research, 93(1-3): 179-187.

Dong Q S. 1997. Physical characteristics of the sand and dust in different deserts of China. Chinese Journal of Radio Science, 12(1): 15-25. (in Chinese)

Fukao S, Wakasugi K, Sato T, et al. 1985. Direct measurement of air and precipitation particle motion by very high frequency Doppler radar. Nature, 316(6030): 712-714.

Gage K S, Williams C R, Ecklund W L. 1996. Application of the $915 \mathrm{MHz}$ profiler for diagnosing and classifying tropical precipitating cloud systems. Meteorology and Atmospheric Physics, 59(1-2): 141-151.

Gossard E E, Wolfe D E, Moran K P, et al. 1998. Measurement of clear-air gradients and turbulence properties with radar wind profilers. Journal of Atmospheric and Oceanic Technology, 15(2): 321-342.

Hashiguchi H, Fukao S, Tsuda T, et al. 1996. An oyerview of the planetary boundary layer observations over equatorial Indonesia with an L-band clear-air Doppler radar. Contributions to Atmospheric Physics, 69(1): 13-25.

He P. 2006. Phased Array Wind Profiler Radar. Beijing: China Meteorological Press, 3-10. (in Chinese)

Hermawan E, Tsuda T. 1999. Estimation of turbulence energy dissipation rate and vertical eddy diffusivity with the MU radar RASS. Journal of Atmospheric and Solar-Terrestrial Physics, 61(15): 1123-1130.

Hocking W K. 1983. On the extraction of atmospheric turbulence parameters from radar backscatter Doppler spectra-I. Theory. Journal of Atmospheric and Terrestrial Physics, 45(2-3): 89-102.

Hocking W K. 1985. Measurement of turbulent energy dissipation rates in the middle atmosphere by radar techniques: A review. Radio Science, 20(6): 1403-1422.

Kuo Y H, Donall E G, Shapiro M A. 1987. Feasibility of short-range numerical weather prediction using observations from a network of profilers. Monthly Weather Review, 115(10): 2402-2427.

Lothon M, Campistron B, Jacoby-Koaly S, et al. 2002. Comparison of radar reflectivity and vertical velocity observed with a scannable C-band radar and two UHF profilers in the lower troposphere. Journal of Atmospheric and Oceanic Technology, 19(6): 899-910.

Ralph F M. 1995. Using radar-measured radial vertical velocities to distinguish precipitation scattering from clear-air scattering. Journal of Atmospheric and Oceanic Technology, 12(2): 257-267.

Rao T N, Rao D N, Raghavan S. 1999. Tropical precipitating systems observed with Indian MST radar. Radio Science, 34(5): $1125-1139$.

Ruan Z, He P, Ge R S. 2008. Determination of refractive index structure constant with wind profile radar data. Chinese Journal of Atmospheric Sciences, 32(1): 133-140. (in Chinese)

Wang M Z, Wei W S, Ruan Z, et al. 2013. Application of wind-profiling radar data to the analysis of dust weather in the Taklimakan Desert. Environmental Monitoring and Assessment, 185(6): 4819-4834.

Wang M Z, Wei W S, He Q, et al. 2016. Summer atmospheric boundary layer structure in the hinterland of Taklimakan Desert, China. Journal of Arid Land, 8(6): 846-860.

You L G, Ma P M, Chen J H, et al. 1991. A case study of the aerosol characteristics in the lower troposphere during a dust storm event. Quarterly Journal of Applied Meteorology, 2(1): 13-21. (in Chinese)

Zhang P C, Wang Z H. 1995. Basis of Atmospheric Microwave Remote Sensing. Beijing: China Meteorological Press, 79-100. (in Chinese)

Zhang P C, Du B Y, Dai T P. 2001. Radar Meteorology ( $2^{\text {nd }}$ ed.). Beijing: China Meteorological Press, 177-189. (in Chinese) 